\title{
Ankara Üniversitesi Tıp Fakültesi Dönem 3 Öğrencilerinde Sosyal Ortamlardaki Gelişmeleri Kaçırma Korkusunun Değerlendirilmesi ve İlişkili Faktörler
}

\section{Evaluation of Fear of Missing the Developments in Social Environments and Related Factors in 3rd Grade Students of Ankara University Faculty of Medicine}

\author{
Belgin Oral ${ }^{1}$, Aslı Şimşek², Oğuzhan Yıldız², Abrek Zeki Ural², Eren Bahadır Aras², Hasibe Mine Mutlutürk², \\ Meltem Çöl ${ }^{3}$ \\ ${ }^{1}$ SBU, Atatürk Göğüs Hastalıkları ve Gögüs Cerrahisi Eğitim ve Araştırma Hastanesi, Ankara, Türkiye. \\ ${ }^{2}$ Ankara Üniversitesi Tıp Fakültesi Öğrencisi, Ankara, Türkiye. \\ ${ }^{3}$ Ankara Üniversitesi Tıp Fakültesi Halk Sağlığı Ana Bilim Dalı, Ankara, Türkiye.
}

e-mail: belgin.zeybek@hotmail.com, asliisimsimsekk97@gmail.com,oguzhanyildiz9906@gmail.com, uralabrek@gmail.com, erenbahadir.aras@gmail.com, mineeasliturk@gmail.com, meltemcol@yahoo.com.

ORCID: 0000-0002-2246-4733

ORCID: 0000-0002-2929-3199

ORCID: 0000-0002-0040-4158

ORCID: 0000-0002-6101-0806

ORCID: 0000-0002-4158-3164

ORCID: 0000-0003-3208-9639

*Sorumlu yazar/ Corresponding Author: Belgin Oral

Gönderim Tarihi / Received: 03.03.2021

Kabul Tarihi / Accepted: 11.06.2021

DOI: $10.34087 /$ cbusbed. 885140

\section{$\ddot{O} z$}

Giriş ve Amaç: Sosyal medya, bireylere sağladığı kolaylıkların yanı sıra 'Sosyal Ortamlarda Gelişmeleri Kaçırma Korkusu' gibi ciddi bir sorunu da beraberinde getirmiştir. Teknoloji çağının yaşanılan ciddi bir Halk Sağlığı konusu olan sosyal ortamlarda gelişmeleri takip etmek ve bu gelişmeleri kaçırma korkusu tıp öğrencileri için de oldukça önemlidir. Bu çalışmanın amacı dönem 3 öğrencilerinde "Sosyal Ortamlarda Gelişmeleri Kaçırma Korkusu” ve ilgili faktörleri belirlemektir.

Gereç ve Yöntemler: Çalışma kesitsel nitelikte olup Ankara Üniversitesi Tıp Fakültesi (AUTF) 3. Sınıf öğrencilerinde Mart 2020 tarihinde gerçekleştirilmiş, 405 öğrenciden ulaşılan ve verileri tam olan 336 öğrenci ile tamamlanmıştır. Veriler 21 sorudan oluşan anket formu ve Przybylski tarafindan geliştirilmiş (2013); Türkçe geçerlilik ve güvenilirliği yapılmış olan "Sosyal Ortamlarda Gelişmeleri Kaçırma Korkusu Ölçeği”" (GKKÖ) uygulanarak toplanmıştır. Analizlerde tanımlayıcı istatistikler yanısıra Pearson ki-kare, t-testi, tek yönlü Anova, Pearson korelasyonu kullanılmıştır. AÜ Tıp Fakültesi Dekanlığı ve Öğrenci Araştırmaları Etik Kurulu izni ve öğrencilerin yazılı onamlarıyla çalışma uygulanmıştır.

Bulgular: Öğrencilerin ortalama yaşı $20.9 \pm 1.5$ yıl ve \%52.4’ü kadındır. Gün içinde internette geçirilen süre ortalama $4.0 \pm 1.9$ saattir ve derste telefonlarını kontrol etme sayısı ortalama $10.8 \pm 13.8$, en çok kullandıkları üç sosyal medya WhatsApp (\%82.7), Youtube (\%79.5) ve İnstagram (\%53.9)'dır. Öğrencilerin GKKÖ puan ortalamaları 24.0 \pm 6.6 'dır. Ölçek puanı ile cinsiyet, uyruk, ebeveynlerinin öğrenim düzeyi ve gelir durumu arasında bir ilişsi yokken, yaşamından memnun olanlarda ölçek puanları düşüktür. WhatsApp, Youtube, İnstagram, Twitter ve Snapchat uygulamalarını kullananlarda ve bildirim geldiğinde hemen bakanlarda GKKÖ puanları anlamlı olarak yüksek bulunmuştur.

Sonuç: Öğrenciler günde ortalama 4 saati internette geçirmekte, derslerde sıklıkla telefonlarını kontrol etmekte olup GKK; yaşamından memnun olanlarda düşük, çeşitli sosyal medya araçlarını kullananlarda, bildirimlerine fazla bakanlarda yüksek bulunmuştur. Eğitim programları içerisinde sosyal medya bağımlılığı hakkında farkındalık sağlanmalı, yaşam memnuniyetlerini arttırıcı sosyal destek verilmelidir. 
Anahtar kelimeler: Gelişmeleri kaçırma korkusu, Tıp öğrencileri, Sosyal medya.

\begin{abstract}
Objective: The fear of following developments and missing out on these developments in the social environments experienced in the technological age is also very important for medical students. The aim of this study is to determine the "Fear of Missing Developments in Social Environments (FoMO)" and related factors in 3rd grade students.

Materials and Methods: The study is of a cross-sectional type and was completed in March 2020 with 336 students in the third year of Ankara University Medical Faculty. The data were collected by applying a questionnaire form consisting of 21 questions and the FoMO scale which was developed by Przybylski (2013). Besides descriptive statistics, Pearson's chi-square, t-test, one-way Anova, and Pearson correlation were used in the analyzes.

Results: The average age of the students was $20.9 \pm 1.5$ years and $52.4 \%$ of them were women. The average time spent on the internet during the day was $4.0 \pm 1.9$ hours, and the average number of checking their phones in class was $10.8 \pm 13.8$, the three most frequently used social media were WhatsApp, Youtube and Instagram. The students' mean FoMO score is $24.0 \pm 6.6$. The scale scores were low in those who were satisfied with their lives. Those who used WhatsApp, Youtube, Instagram, Twitter and Snapchat applications and those who immediately receive a notification have found significantly higher FoMO scores.
\end{abstract}

Conclusion: Awareness about social media addiction should be provided in education programs, and social support should be given to increase life satisfaction.

Keywords: Fear of Missing Developments, Medical Students, Social media.

\section{Giriş}

Teknolojinin hızlı gelişimiyle birlikte insanların kullandıkları iletişim yöntemleri de büyük bir değişim göstermiş̧ir. Günümüzde en çok kullanılan iletişim yöntemlerinden biri de sosyal medyadır [1]. İnsanlar sosyal medyayı; takip ettiği insanların hayatından haberdar olmak, seslerini geniş kitlelere duyurabilmek, aile ve arkadaşlarıyla iletişimlerini sürekli kılabilmek ve kendilerini ifade etmek için kullanırlar. Bireylerin birbirlerinden haberdar olmalarına olanak sağlayan, iletişim kolaylığı sağlayan sosyal medya, bu kolaylıklarının yanında gelişmeleri kaçırma korkusu gibi bazı olumsuzlukları da beraberinde getirmektedir [2]. Amerikalı bilim insanları tarafindan 'Fear of Missing Out (FoMO)' olarak tanımlanan bu durum Türkçe'de 'Gelişmeleri Kaçırma Korkusu (GKK)' olarak adlandırılmıştır [3,4].

Bireylerin sosyal olarak dışlanma korkuları sonucu oluşan GKK [5]; başkalarının kendisi yokken güzel bir deneyimi yaşayabileceğine dair şüphe, heyecan verici ya da ilginç bir olayın başka bir yerde gerçekleșebileceği endişesi olarak tanımlanmaktadır [3,5]. Genellikle kavramsal psikolojinin bir konusu olarak düşünülen GKK, bireylerin psikolojik durumlarının bir türünü yansitmaktadır [6]. Literatürde bu olgunun temellendirilmesinde çoğunlukla "Öz Belirleme Kuramı”na atıf yapılmaktadır [7]. Öz belirleme kuramında özerklik, yeterlik ve ilişkili olma kavramları olmak üzere üç psikolojik ihtiyaç yer almaktadır [7]. Bu ihtiyaçların karşılanmasındaki eksiklik bireylerde gelişmeleri kaçırma korkusuna neden olmaktadır. Gelişmeleri kaçırma korkusunun sosyal medya ile ilişkilendirilmesi, doğrudan bu ihtiyaçların karşılanması amacıyla kurulan ilişkilerin güçlendirilmesi ve sosyal medyadaki insanlarla bağlantı kurmak amacıyla yapılabilirken, dolaylı olarak gelişmeleri kaçırma korkusunun etkisiyle sosyal medyada etkileşim kurma isteği olarak da görülebilir [8]. GKK, son y1llarda popüler medya organlarında görülmeye başlanan bir kavram olmakla birlikte, uzun zamandır var olan depresyon, anksiyete ve fiziksel semptomlarla ilişkilendirilen, modern dijital çağın gelişmesiyle birlikte önem kazanan ve şiddetlenen bir problemdir ve sosyal ağ bağımlığının önemli bir öngörücüsü ve bileşeni olarak görülmektedir $[9,10]$.

Akıllı telefonların satın alma kolaylıkları ve son yıllarda hızla yaygınlaşması bireylerin daha rahat sosyal medyada paylaşımlarda bulunmasına, gerek mesaj gerekse gelen postalarına bakmalarına olanak sağlamış ve güncellemelerin kontrolü sırasında artan akı1lı telefon kullanımı GKK'nın ortaya çıkmasıyla yakından ilgili hale gelmiştir [8]. Kişilerin kendilerini bir gruba dahil hissetme ve olduklarından farklı görünme arzusu, popüler olma kaygısı, beğenilmeme veya reddedilme korkusu da kişilerde GKK düzeyini arttıran sebeplerdendir [11].

Türkiye'de sosyal medya kullanımının tüm bireyler için \%63 olduğu ve tüm dünyada gelişmeleri kaçırma korkusuna önemli ölçüde katk1 sağlayan Facebook, Twitter ve Snapchat gibi uygulamaların Türkiye'de de etkili olduğu görülmüştür [12]. Ergenlerde yapılmış bir çalışmada GKK düzeyleri yüksek olanların daha yoğun Facebook kullandıkları, Facebook'ta popüler olmadıklarında ve çevrimiçi olmadıklarında daha fazla stres yaşadıkları gösterilmiştir [11].

İnternet kullanımı ile mobil telefon kullanım bağımlılığı ve bireylerin kendilerini yalnız hissetmeleri arasında doğrudan ilişsiler bulunmaktadır. Bir araştırmada, GKK düzeyleri yüksek olan öğrencilerde paylaşım yapma ihtiyacının görüldüğü, sosyal izolasyon miktarının arttığ ve bu izolasyonun depresyona neden olabileceği belirlenmiş̧tir [13]. Ortaya çıkışı çok yakın bir tarih olan GKK kavramı hakkında yapılmış olan çalışmalar sınırlı sayıdadır. Aşırı derecede sosyal medya kullanımına bağlı olarak ortaya çıkan depresyon, anksiyete, kişinin kendini yalnız hissetme durumu, aidiyet duygusunun kaybı, akademik başarıda düşüş, uykusuzluk, yüz yüze iletişimde azalma, sosyal beceri kaybı, toplum karşsısında kendini ifade etmede güçlük gibi günlük hayatta yaşam kalitesine doğrudan etkisi olan durumların GKK ile olan ilişkisinin gösterilmesi ve 
kişilerin bu kavram hakkında bilgilendirilmesi oldukça önemlidir. Fransa'da yapılmış bir çalışmada 25 yaş altındaki bireylerde ve ayrıca özellikle öğrenciler, emekliler ve işsiz insanlar gibi boş zamanları fazla olan kişilerin sosyal medyayla ilişkisinin daha çok olduğu, bu sebeple GKK düzeylerinin görece yüksek olduğu saptanmıştır [14]. Tıp Fakültesi öğrencileri, yoğun çalışması gereken bir grup olup, GKK bu grubun akademik başarısını etkileyebilir. Bu konuda yapılan çalışmalar yetersiz olup, Tıp Fakültesi öğrencilerinde GKK düzeyi ve ilişkili faktörlerin belirlenmesi önem göstermektedir. Bu çalışmada 2019-2020 eğitimöğretim yılında, Ankara Üniversitesi Tıp Fakültesi 3.Sınıf öğrencilerinde sosyal ortamlarda GKK düzeyinin belirlenmesi ve ilişkili etmenlerin araştırılması amaçlanmıştır.

\section{Materyal ve Metot}

\subsection{Metot}

Kesitsel tipteki bu çalışma, 2019-2020 eğitim ve öğretim yılında okuyan Ankara Üniversitesi Tip Fakültesinde 3. Sınıf öğrencilerinde 2020 Mart ayında gerçekleştirilmiştir. 3. sınıf, öğrencilerin fakülteye adapte olduğu, ancak ders yoğunluğunun da yüksek olduğu bir dönem olup bu grupta çalışmanın yapılması uygun bulunmuştur.

Üçüncü sınıftaki öğrenci sayısı 405 olup öğrencilerin tamamına ulaşılması hedeflenmiş, örneklem yapılmamış ve toplamda 370 öğrenciye ulaşılmıştır. Araştırmaya katılan 370 öğrencinin 34'ünün anket verileri eksik olduğu için toplamda 336 (\%83) öğrencinin verileriyle çalışma tamamlanmıştır. Öğrenciler araştırma hakkında bilgilendirilip yazılı onamları alındıktan sonra, gözlem altında anket yoluyla veriler toplanmıştır.

Anket formu; öğrencilerin yaşı, cinsiyeti, annebabasının öğrenim düzeyi, nerede kaldığı, ekonomik durumu gibi sosyodemografik özellikleriyle, fiziksel aktivite ve diğer alışkanlıklarıyla ilgili, sosyal medyayı kullanma durumlarını değerlendirmeye yönelik 5'i açık uçlu olmak üzere 21 adet sorudan ve Sosyal Ortamlarda Gelişmeleri Kaçırma Korkusu Ölçeğinden (GKKÖ) oluşmaktadır. Çalışmanın bağımlı değişkeni GKKÖ puanı olup, bağımsız değişkenleri ise yaşı, cinsiyeti, uyruğu, sosyoekonomik durumu, derslerde başarı durumu, yaşam memnuniyeti, sigara ve alkol kullanma durumu, egzersiz yapma, ak1llı telefon ve sosyal medya kullanım özellikleri gibi bazı değişkenler oluşturmaktadır. Sosyoekonomik durumu belirlemek için ebeveynlerin öğrenim durumu ve gelir düzeylerine bakılmıştır. Akademik başarı için genel not ortalaması ve yaşam memnuniyeti için de öznel değerlendirme yapılmıştır. Akıllı telefon kullanımı konusunda; telefona bakma sıklıkları, uyumadan önce ve uyandıktan sonraki telefon kullanımları sorgulanmıştır. Sosyal medya kullanımı için; sosyal medya hesabı sayısı, hesapların kullanım süreleri, aldıkları bildirimlere bakma süreleri değerlendirilmiştir.

\subsection{Kullanılan ölçek}

Sosyal Ortamlarda Gelişmeleri Kaçırma Korkusu Ölçeği (GKKÖ) 2013 yılında Przybylski tarafından geliştirilen 10 sorudan oluşan beşli likert tipindedir (3). Ölçek kişilerin sosyal ortamlarda gelişmelerle ilgili öz değerlendirmeleri içermektedir. Ölçekte yer alan her bir madde 1 ile 5 arasında bir puan almaktadır (1=hiç doğru değildir, 5=aşırı şekilde doğrudur). Ölçekten alınabilecek puanlar 10 ile 50 arasında değişmekte olup, ölçeğin herhangi bir kesim noktası yoktur. Ölçekten alınan puanlar arttıkça bireyin sosyal ortamlardaki gelişmeleri kaçırma korkusunun olma olasılığı da artmaktadır. GKKÖ’nin Türkçe geçerlilik ve güvenirliliği Gökler ve ark.'ları tarafından 2016 yılında yapılmış olup Cronbach alfa katsayısı 0.81 olarak bulunmuştur [4].

\subsection{Istatistiksel analiz}

Araştırma sonunda anket formu aracılığı ile elde edilen veriler istatistik paket programına (IBM SPSS v22) girilmiştir. İstatistiksel değerlendirmede tanımlayıcı istatistikler yanısıra, Pearson ki-kare testi, normal dağılıma uygunluğuna bakmak için Kolmogorov Smirnov testi uygulanmıştır. Veriler normal dağılıma uyduğu için t-testi ve tek yönlü ANOVA testi (post hoc Tukey) kullanılmıştır. Değişkenler arasındaki ilişkiyi göstermek için Pearson Korelasyon katsayısı kullanılmıştır. İstatistiksel olarak farkın önemliliği $\mathrm{p}<0,05$ olarak kabul edilmiştir.

2.4. Izinler

Araştırma, AÜ Tıp Fakültesi Dekanlığı ve 2019/9904 yıl/sayılı Öğrenci Araştırmaları Etik Kurulu izni ve öğrencilerin yazılı onamları alındıktan sonra uygulanmıştır. Çalışma Helsinki Deklerasyonu 2008 prensiplerine uygun olarak yapılmıştır.

\section{Bulgular ve Tartıșma}

\subsection{Bulgular}

Öğrencilerin yaş ortalaması $20.9 \pm 1.5$ (min-max:19-40) y1l, \%52.4'ü kadın ve \%6.0'1 yabancı uyrukludur. Ailelerin gelir durumu $\% 89.3$ oranında yeterli olarak belirtilirken, anne ve babaları üniversite mezunu olanlar sirasiyla \%53.0 ve \%74.4'dür. Katılımcilardan \%99.1'i akıllı telefon kullanmakta olduğunu, \%76.5'i dizüstü bilgisayar, \%24.7'si ise tableti olduğunu ifade etmiştir.

Öğrencilerin GKKÖ puan ortalamaları 24.0 06.6 (minmax:10-45)'dır. Ölçek puanı ile cinsiyet, uyruk, öğrencilerin ebeveynlerinin öğrenim düzeyi, ailelerinin gelir durumu arasında anlamlı bir ilişki bulunmamıştır. İstatistiksel olarak anlamlı olmasa da annesi ve babası ortaokul ve altında öğrenim düzeyine sahip olanlarda ölçek puanları daha düşük bulunmuştur (Tablo 1).

Ölçek puanları ile akıllı telefon, diz üstü bilgisayar ve tablet gibi teknolojik cihazlara sahip olunması arasında istatistiksel olarak anlamlı ilişki görülmese de akıllı telefonu olmayan ve interneti olmayan bir cep telefonuna sahip öğrencilerde ölçek puanlarının daha düşük olduğu görülmektedir (Tablo 2).

Çalışmamıza katılanların ortalama $6.4 \pm 3.2$ (min-max: 0-20) yildır sosyal medya hesabı bulunmaktadır ve 
Tablo 1. Öğrencilerin bazı sosyo-demografik özelliklerine göre GKKÖ puan ortalamaları

\begin{tabular}{|c|c|c|c|c|c|}
\hline \multicolumn{2}{|l|}{ Değişkenler } & \multicolumn{2}{|c|}{ Sayı ve yüzdeler } & \multicolumn{2}{|c|}{ GKKÖ puan ortalamaları } \\
\hline & & $\mathbf{n}$ & $\%$ & Ort./sd & $\mathbf{p}$ \\
\hline \multirow[t]{2}{*}{ Cinsiyet } & Kadın & 176 & 52.4 & $24.5 \pm 6.2$ & \multirow[t]{2}{*}{$\mathrm{p}=0,135^{*}$} \\
\hline & Erkek & 160 & 47.6 & $23.4 \pm 6.9$ & \\
\hline \multirow[t]{2}{*}{ Uyruk } & $\mathrm{TC}$ & 316 & 94.0 & $24.1 \pm 6.6$ & \multirow[t]{2}{*}{$\mathrm{p}=0,246^{*}$} \\
\hline & Yabanc1 & 20 & 6.0 & $22.4 \pm 6.2$ & \\
\hline \multirow[t]{3}{*}{ Annenin eğitim } & Orta okul ve altı & 85 & 25.3 & $22.7 \pm 6.3$ & \multirow[t]{3}{*}{$\mathrm{p}=0,068 * *$} \\
\hline & Lise & 73 & 21.7 & $25.0 \pm 5.5$ & \\
\hline & Üniversite & 178 & 53.0 & $24.2 \pm 7.0$ & \\
\hline \multirow[t]{3}{*}{ Babanın eğitim } & Orta okul ve altı & 29 & 8.6 & $21.4 \pm 6.0$ & \multirow[t]{3}{*}{$\mathrm{p}=0,069 * *$} \\
\hline & Lise & 57 & 17.0 & $23.9 \pm 6.1$ & \\
\hline & Üniversite & 250 & 74.4 & $24.3 \pm 6.7$ & \\
\hline \multirow[t]{2}{*}{ Ailenin gelir durumu } & Yetersiz & 36 & 10.7 & $23.6 \pm 7.1$ & \multirow[t]{2}{*}{$\mathrm{p}=0,684^{*}$} \\
\hline & Yeterli & 300 & 89.3 & $24.1 \pm 6.5$ & \\
\hline \multicolumn{2}{|l|}{ Toplam } & 336 & 100.0 & $24.0 \pm 6.6$ & \\
\hline
\end{tabular}

*Student $t$ Testi, **One Way ANOVA

Tablo 2. Öğrencilerin sahip olduğu teknolojik cihazlara göre GKKÖ puan ortalamaları

\begin{tabular}{|c|c|c|c|c|c|}
\hline \multicolumn{2}{|l|}{ Değişkenler } & \multicolumn{2}{|c|}{ Sayı ve yüzdeler } & \multicolumn{2}{|c|}{ GKKÖ puan ortalamaları } \\
\hline & & $\mathrm{n}$ & $\%$ & Ort./sd & $\mathrm{p}$ \\
\hline \multirow[t]{2}{*}{ Akıllı telefon } & Evet & 333 & 99.1 & $24.0 \pm 6.5$ & \multirow[t]{2}{*}{0,377} \\
\hline & Hayır & 3 & 0.9 & $20.7 \pm 10.1$ & \\
\hline \multirow[t]{2}{*}{ Dizüstü bilgisayar } & Evet & 257 & 76.5 & $24.3 \pm 6.7$ & \multirow[t]{2}{*}{0,130} \\
\hline & Hayır & 79 & 23.5 & $23.0 \pm 5.9$ & \\
\hline \multirow[t]{2}{*}{ Tablet } & Evet & 83 & 24.7 & $24.5 \pm 7.1$ & \multirow[t]{2}{*}{0,403} \\
\hline & Hayır & 253 & 75.3 & $23.8 \pm 6.4$ & \\
\hline \multirow[t]{2}{*}{ İnternetsiz cep telefonu } & Evet & 10 & 3.0 & $20.7 \pm 7.1$ & \multirow[t]{2}{*}{0,106} \\
\hline & Hayır & 326 & 97.0 & $24.1 \pm 6.5$ & \\
\hline
\end{tabular}

\section{Student $t$ Testi}

cinsiyetler arasında fark yoktur (K:6.2 $\pm 2.8 \mathrm{y} 1 \mathrm{l}-$ E:6.6 \pm 3.6 y1l (p:0.247)). En sik kullanılan sosyal medya araçları ise; (\%96.7) WhatsApp, (\%82.7) Youtube ve (\%79.5) İnstegram'dır. Ölçek puanları WatsApp, Youtube, İnstegram, Twitter ve Snapchat kullandığını bildiren öğrencilerde anlamlı olarak yüksek bulunmuştur $(\mathrm{p}<0,05)$. İstatistiksel olarak bir anlamlılık bulunmasa da Reddit, Ekși sözlük ve Tumblr kullanan öğrencilerin de ölçek puanları daha yüksektir (Tablo 3).

Öğrencilerin \%93.8'i uyumadan telefonunda vakit geçirdiğini ve \%83.9'u ise uyanır uyanmaz bildirimlerini kontrol ettiğini belirtmiştir. Sabah bildirimlerini kontrol etme sıklığı kadın öğrencilerde $\% 88.1$ erkek öğrencilerde ise \%79.4 olup gruplar arasında fark anlamlı bulunmuştur $\left(X^{2}: 4,696, \mathrm{p}=0,030\right)$. Öğrencilerin $\% 37.5$ ' $\mathrm{i}$ bildirimleri fark eder etmez baktığını belirtmiş̧tir. Ölçek puanları uyumadan önce telefonuyla vakit geçiren, sabah uyanır uyanmaz bildirimlerini kontrol eden ve bildirimleri gelince hemen bakanlarda anlamlı olarak yüksek bulunmuştur $(\mathrm{p}<0,05)$ (Tablo4).
Öğrencilerin \%16.7'si sigara kullanmakta, \%59.2'si ise hiçbir zaman alkol kullanmadığını belirtmiş ve $\% 38.4$ 'ü düzenli olarak spor yaptığını ve kendi değerlendirmesine göre \%62.2'si yaşamından memnun olduğunu ifade etmiştir. Ölçek puanları ile sigara, alkol kullanma ve düzenli spor yapma durumu arasında anlamlı bir ilişki bulunmamış ancak yaşamından memnun olan öğrencilerde ölçek puanları daha düşük bulunmuştur $(\mathrm{p}<0.05)$ (Tablo 5).

Öğrencilerin gün içinde internette geçirdikleri süre ortalama 4.0 \pm 1.9 saattir (min-max: 0.5-12). Normal bir ders zamanında ders dışı nedenlerle telefonlarını kontrol etme sıklı̆ğ $10.8 \pm 13.8$ (min-max:0-100) ve öğrencilerin not ortalaması 4 üzerinden $2.9 \pm 0.4$ (minmax:1.3-3.9)'dür. Gün içinde internette geçirilen süre ve not ortalamalarıyla ölçek puanları arasında korelasyon bulunmamıștır. Ancak sosyal medyayı kullanım yılları ve derslerde ders dışı nedenlerle bildirimlerini kontrol etme sıklıkları arttıkça ölçek puanları da artmakta yani bu iki değişken ile ölçek puanları arasında pozitif yönde bir korelasyon bulunmaktadır (Tablo 6). 
Tablo 3. Öğrencilerin sıklıkla kullandığı sosyal medya araçlarına göre GKKÖ puan ortalamaları

\begin{tabular}{|c|c|c|c|c|c|}
\hline \multicolumn{2}{|l|}{ Değişkenler } & \multirow[b]{2}{*}{$\mathbf{n}$} & \multirow[b]{2}{*}{$\%$} & \multicolumn{2}{|c|}{ GKKÖ puan ortalamaları } \\
\hline & & & & Ort./sd & $\mathbf{p}^{*}$ \\
\hline \multirow{2}{*}{ WhatsApp } & Kullanan & 325 & 96.7 & $24.1 \pm 6.5$ & \multirow{2}{*}{0,040} \\
\hline & Kullanmayan & 11 & 3.3 & $20.0 \pm 7.3$ & \\
\hline \multirow[t]{2}{*}{ Youtube } & Kullanan & 278 & 82.7 & $24.5 \pm 6.5$ & \multirow[t]{2}{*}{0,003} \\
\hline & Kullanmayan & 58 & 17.3 & $21.7 \pm 6.2$ & \\
\hline \multirow[t]{2}{*}{ İnstagram } & Kullanan & 267 & 79.5 & $24.7 \pm 6.3$ & \multirow[t]{2}{*}{$<0,001$} \\
\hline & Kullanmayan & 69 & 20.5 & $21.3 \pm 7.0$ & \\
\hline \multirow[t]{2}{*}{ Twitter } & Kullanan & 181 & 53.9 & $24.9 \pm 6.6$ & \multirow[t]{2}{*}{0,009} \\
\hline & Kullanmayan & 155 & 46.1 & $23.0 \pm 6.4$ & \\
\hline \multirow[t]{2}{*}{ Snapchat } & Kullanan & 137 & 40.8 & $25.4 \pm 6.3$ & \multirow[t]{2}{*}{0,002} \\
\hline & Kullanmayan & 199 & 59.2 & $23.1 \pm 6.6$ & \\
\hline \multirow[t]{2}{*}{ Facebook } & Kullanan & 135 & 40.2 & $24.5 \pm 7.2$ & \multirow[t]{2}{*}{0,235} \\
\hline & Kullanmayan & 201 & 59.8 & $23.7 \pm 6.1$ & \\
\hline \multirow[t]{2}{*}{ Telegram } & Kullanan & 46 & 13.7 & $24.7 \pm 6.4$ & \multirow[t]{2}{*}{0,416} \\
\hline & Kullanmayan & 290 & 86.3 & $23.9 \pm 6.6$ & \\
\hline \multirow[t]{2}{*}{ Pinterest } & Kullanan & 43 & 12.8 & $23.5 \pm 6.0$ & \multirow[t]{2}{*}{0,581} \\
\hline & Kullanmayan & 293 & 87.2 & $24.1 \pm 6.7$ & \\
\hline \multirow[t]{2}{*}{ Reddit } & Kullanan & 41 & 12.2 & $25.5 \pm 6.1$ & \multirow[t]{2}{*}{0,117} \\
\hline & Kullanmayan & 295 & 87.8 & $23.8 \pm 6.6$ & \\
\hline \multirow[t]{2}{*}{ Ekşi Sözlük } & Kullanan & 39 & 11.6 & $25.5 \pm 8.2$ & \multirow[t]{2}{*}{0,121} \\
\hline & Kullanmayan & 297 & 88.4 & $23.8 \pm 6.3$ & \\
\hline \multirow[t]{2}{*}{ Tumblr } & Kullanan & 16 & 4.8 & $26.3 \pm 7.5$ & \multirow[t]{2}{*}{0,150} \\
\hline & Kullanmayan & 320 & 95.2 & $23.9 \pm 6.5$ & \\
\hline \multirow[t]{2}{*}{ Linkedln } & Kullanan & 15 & 4.5 & $24.0 \pm 8.5$ & \multirow[t]{2}{*}{0,997} \\
\hline & Kullanmayan & 321 & 95.5 & $24.0 \pm 6.5$ & \\
\hline
\end{tabular}

*Student $t$ Test $i$

Tablo 4. Öğrencilerin bildirimlerine bakma durumlarına göre GKKÖ puan ortalamaları

\begin{tabular}{|c|c|c|c|c|c|}
\hline \multirow{2}{*}{\multicolumn{2}{|c|}{ Değişkenler }} & \multicolumn{2}{|c|}{$\begin{array}{l}\text { Sayı ve } \\
\text { yüzdeler }\end{array}$} & \multicolumn{2}{|c|}{ GKKÖ puan ortalamaları } \\
\hline & & $\mathbf{n}$ & $\%$ & Ort./sd & $\mathbf{p}$ \\
\hline \multirow{2}{*}{$\begin{array}{l}\text { Uyumadan önce akıllı telefon kullanım } \\
\text { durumu }\end{array}$} & Evet & 315 & 93.8 & $24.2 \pm 6.5$ & \multirow{2}{*}{$\mathrm{p}=\mathbf{0 , 0 5 4} *$} \\
\hline & Hayır & 21 & 6.3 & $21.3 \pm 7.4$ & \\
\hline \multirow{2}{*}{$\begin{array}{l}\text { Uyanir uyanmaz bildirimlere bakma } \\
\text { durumu }\end{array}$} & Evet & 282 & 83.9 & $24.5 \pm 6.5$ & \multirow[t]{2}{*}{$\mathrm{p}=0,003^{*}$} \\
\hline & Hayır & 54 & 16.1 & $21.6 \pm 6.3$ & \\
\hline \multirow[t]{3}{*}{ Bildirimleri fark edince bakma zamanı } & Bakmam & 7 & 2.1 & $18.9 \pm 9.6^{\mathrm{a}}$ & \multirow[t]{3}{*}{$\mathbf{p}<0,001 * *$} \\
\hline & Hemen bakarım & 126 & 37.5 & $25.7 \pm 6.6^{\mathrm{b}}$ & \\
\hline & Müsait olunca & 203 & 60.4 & $23.2 \pm 6.2^{\mathrm{a}}$ & \\
\hline
\end{tabular}

*Student $t$ Testi, ** One Way ANOVA (posthoc Tukey) a,b: Her satırda aynı harfi taşımayan gruplar arasındaki fark önemlidir $(p<0.05$ )

\subsection{Tartı̧̧ma}

Son yıllarda çağımızın ciddi bir sorunu olan internet bağımlılı̆̆ıyla ilişkili olan GKK, yani sosyal ortamlardaki gelişmeleri kaçırma korkusu sorunlu akı1lı telefon kullanmayla, bazı psikopatolojilere eşlik etmesiyle oldukça önemli bir konudur. Sosyal medyadaki popüler ağların, kanalların takibi ve buradaki bildirimlerin gelişmeleri kaçırma korkusu ile ilişkili olabileceği bir gerçektir. Bireyleri sürekli gelen bildirimlerle kendilerine bağlayan bu sosyal medya araçları insanlar arasında iletişim ve haberleşme kolaylığının ötesinde ciddi bir bağımlılık hatta bazı anksiyete depresyon gibi ruhsal ve uyku bozukluğu gibi fiziksel rahatsızlıklar da oluşturmaktadır [15-18]. Literatürde GGK'nun depresyon ve sorunlu akıllı telefon kullanımında kilit rol oynadığını ifade eden, sosyal medya kullanımı üzerinde etkisinin olduğunu gösteren bazı çalışmalar da mevcuttur $[19,20]$.

Literatürde sınırlı çalışma olması ve az bilinen bir kavram olması nedeniyle yapılan bu çalışmada Tıp 
fakültesi dönem 3 öğrencilerin GKKÖ puan ortalamaları 24.0 olarak düşük bulunmuştur.
Tozkoparan ve Kuzu öğretmen adaylarında ölçek puanını 28.6, Hoşgör ve ark.'ları üniversite

Tablo 5. Öğrencilerin bazı sağlık göstergelerine göre GKKÖ puan ortalamaları

\begin{tabular}{|c|c|c|c|c|c|}
\hline \multicolumn{2}{|l|}{ Değişkenler } & \multicolumn{2}{|c|}{ Sayı ve yüzdeler } & \multicolumn{2}{|c|}{ GKKÖ puan ortalamalar } \\
\hline & & $\mathbf{n}$ & $\%$ & Ort./sd & $\mathbf{p}$ \\
\hline \multirow[t]{2}{*}{ Sigara kullanma durumu } & Evet & 56 & 16.7 & $23.9 \pm 6.4$ & \multirow[t]{2}{*}{$\mathrm{p}=0,428^{*}$} \\
\hline & Hayır & 280 & 83.3 & $24.6 \pm 7.4$ & \\
\hline \multirow[t]{2}{*}{ Alkol kullanma durumu } & Evet & 137 & 40.8 & $24.7 \pm 6.9$ & \multirow[t]{2}{*}{$\mathrm{p}=0,101 *$} \\
\hline & Hayır & 199 & 59.2 & $23.5 \pm 6.3$ & \\
\hline \multirow[t]{2}{*}{ Spor yapma durumu } & Evet & 129 & 38.4 & $23.8 \pm 7.3$ & \multirow[t]{2}{*}{$\mathrm{p}=0,600^{*}$} \\
\hline & Hayır & 207 & 61.6 & $24.2 \pm 6.1$ & \\
\hline \multirow[t]{3}{*}{ Yaşam memnuniyeti } & Memnun & 209 & 62.2 & $23.2 \pm 6.3^{\mathrm{a}}$ & \multirow[t]{3}{*}{$\mathbf{p}=0,013 * *$} \\
\hline & Kararsiz & 81 & 24.1 & $25.1 \pm 6.7^{\mathrm{b}}$ & \\
\hline & Memnun değil & 46 & 13.7 & $25.8 \pm 6.9^{b}$ & \\
\hline
\end{tabular}

*Student t Testi, ** One Way ANOVA (posthoc Tukey) a,b: Her satırda aynı harfi taşımayan gruplar arasındaki fark önemlidir (p<0.05

Tablo 6. Öğrencilerin bazı değişkenleri ile GKKÖ puan ortalamaları arasındaki korelasyonu

\begin{tabular}{|l|l|l|c|}
\hline Değişkenler & \multicolumn{2}{l|}{ Ortalama ve korelasyon } \\
\cline { 2 - 4 } & Ort./sd & \multicolumn{2}{l|}{ Krlsyn. katsayısı } \\
\hline Gün içinde internette geçirilen süre (saat) & $4.0 \pm 1.9$ & 0,050 & 0,361 \\
\hline $\begin{array}{l}\text { Ders zamanında ders dışı nedenlerle bildirimleri kontrol } \\
\text { etme sıklığı }\end{array}$ & $10.8 \pm 13.8$ & $0,206^{*}$ & $<\mathbf{0 , 0 0 1}$ \\
\hline Sosyal medyayı kullanma süresi (yıl) & & & $\mathbf{0 , 0 0 2}$ \\
\hline Öğrencilerin not ortalamaları (4 üzerinden) & $6.4 \pm 3.2$ & $0,165^{*}$ & 0,220 \\
\hline
\end{tabular}

*Korelasyon 0,01 düzeyinde anlamlı

öğrencilerinde 28.6, Kargın ve ark.'ları hemșirelik öğrencilerinde 23.3 ve Yuan ve ark.'ları Çin'de üniversite öğrencilerinde 25.1, Qutishat ve Sharour ise üniversite öğrencilerinde 28.9 bulmuşlardır $[2,8,17,19,21]$. Bizim çalışmamızda ölçek puanlarının genel olarak düşük bulunması Tıp Fakültesi öğrencilerinin yoğun ders programlarının olmasına bağlanabilir.

Çalışmamızda ölçek puanı ile cinsiyet, uyruk, öğrencilerin ebeveynlerinin öğrenim düzeyi, ailelerinin gelir durumu arasında anlamlı bir ilişki bulunmamıştır. Benzer şekilde Kargın ve ark.'ları da çalışmalarında ölçek puanları ile cinsiyet ve ekonomik durum arasında ilişki bulmamıştır [21]. Coşkun ve Uslu da lise öğrencilerinde yaptıkları çalışmalarında cinsiyete göre ölçek puanlarının değişmediğini göstermiş ancak annelerinin eğitim düzeyi arttıkça ölçek puanlarının da arttığını ifade etmişlerdir [22]. Bizim çalışmamızda da istatistiksel olarak anlamlı olmasa da ebeveynleri orta okul ve altında olanlarda ölçek puanları daha düşüktür. Akıllı telefonların kullanımının cinsiyet ayrımı gözetmeksizin artması ve her bütçe için alım fırsatlarının olması ölçek puanlarının bu değişkenlere göre fark göstermemesini açıklayabilir. Ayrıca annebabaların eğitim düzeylerinin artması çocukları ile iletişim yollarında bu sosyal kanalların kullanımının da arttığını düşündürmektedir. Nitekim çalışmamızda istatistiksel olarak anlamlı olmasa da ak1llı telefonu olmayan ya da interneti olmayan telefona sahip öğrencilerde ölçek puanları daha düşük bulunmuştur. Öyle ki literatürde akıllı telefon kullanımının GKK ile ilişkisini gösteren çalışmalar da mevcuttur [18,23]. Çalışmamızda en sık kullanılan sosyal medya araçları WhatsApp, Youtube ve İnstagram, Twitter, Snapchat ve Facebook olmuştur. Literatürdeki benzer çalışmalarda da sıklıkla kullanılan sosyal medya araçları bizim çalışmamızdaki gibi olup öncelik sıralaması farklıdır [8,24,25]. Bu çalışmalara göre sıklıkla kullanılan sosyal medya araçları arasındaki önceliklerin farklı olması çalışmamızın daha güncel olmasından ve dolayısıyla öğrencilerin tercihlerinin değişmiş olabileceği gibi, diğer araştırmalardaki katılımcıların farklı yaş grubu ve fakültelerden olmasından da kaynaklanabilir. Ayrıca Facebook'un 
Tıp öğrencileri arasında daha az oranda popüler olduğu şeklinde de yorumlanabilir.

$\mathrm{Bu}$ çalışmamızda ölçek puanları WatsApp, Youtube, İnstegram, Twitter ve Snapchat kullandığını bildiren öğrencilerde istatistiksel olarak yüksekti. Gezgin ve ark.'ları ögrretmen adaylarında Twitter, Instagram, Swarm ve Snapchat kullananlarda GKKÖ puanlarını yüksek bulmuş, Beyens ve ark.'ları ergenlerde artan gelişmeleri kaçırma korkusu değerleriyle Facebook kullanımına bağlı stresle ilişkilendirmişler ve Dempsey ve ark.' ları da benzer şekilde üniversite öğrencilerinde sorunlu Facebook kullanımı ile GKK'nun önemli ölçüde ilişkili olduğunu belirtmiştir [11,24,26]. Ayrıca Rozgonjuk ve ark.'ları WhatsApp, Facebook, Instagram ve Snapchat kullanım bozuklukları ile GKK'nun ilişkisini göstermişler ve Belçika'daki ergenlerde yapılan güncel bir çalışmada Facebook, Snapchat, Instagram ve YouTube kullanımının ölçek puanları ile tutarlı bir şekilde ilişkili olduğu da bulgulanmıştır [25,27].

Çalışmamızda öğrencilerin \%93.8'nin uyumadan telefonunda vakit geçirdiği ve \%83.9'unun ise uyanır uyanmaz bildirimlerini kontrol ettiği ve \%37.5'inin bildirimleri fark eder etmez baktığ görülmüştür. Hoşgör ve ark.'larının çalışmalarında da benzer şekilde öğrencilerin \%94.3'ü uyumadan önce telefonunu kontrol etmekte ve sabah uyanınca bildirimlerine bakanların oranı \%81.9'dur [8]. Çalışmamızda GKKÖ puanları uyumadan önce telefonuyla vakit geçiren, sabah uyanır uyanmaz bildirimlerini kontrol eden ve bildirimleri gelince hemen bakanlarda anlamlı olarak yüksek bulunmuştur. Sosyal ortamlardaki gelişmeleri kaçırmaktan endişe eden bireylerin yaşamlarının her anında bu durumu hissetmeleri uyumadan önce ve uyanır uyanmaz ve bildirim gelince hemen bu bildirimleri kontrol etmeleri bilinçaltında bir dürtünün davranış haline dönüştüğünü de göstermektedir.

Çalışmamızda öğrenciler sosyal medya hesaplarını ortalama 6.4 yıldır kullanmaktaydı ve GKKÖ puanları ile pozitif bir korelasyon mevcuttu. Hoşgör ve ark.'larının çalışmalarında da dört yıldan fazla süredir sosyal medyaya sahip olanların oranı \%75.7'dir ve bizim çalışmamızdaki gibi sosyal medya hesabına sahip olma yılları arttıkça, ölçek puanlarının da arttığı görülmektedir [8]. Problemli sosyal medya kullanımına aracılık eden GKKÖ'nün sosyal medya hesaplarına sahip olma süresiyle (y1l) pozitif bir korelasyonda olması beklenen bir durumdur.

Çalışmamızda ders dışı nedenlerle ders sırasında telefonlarındaki bildirimleri kontrol etme sıklığ 10.8 'di ve ölçek puanları ile pozitif yönde korelasyon göstermekteydi ve benzer olarak Barry ve ark.'larının ergenlerde yaptıkları çalışmalarında da sosyal medyayı kontrol etme sıklığı ile GKKÖ puanları arasında pozitif bir ilişki gösterilmiştir [15]. Çalışmamızda ayrıca gün içinde internette geçirilen süre ortalama 4 saatti ancak ölçek puanları ile ilişki yokken, Coşkun ve Muslu akıllı telefonu kullanma saatleri arttıkça yükselen GKKÖ değerlerini göstermişlerdir [22]. Aslında gün içinde internette geçirilen süre ile artan gelişmeleri kaçırma korkusu beklenirken bizim çalışmamızda görülmemesi Tıp Fakültesinde derslerin oldukça yoğun geçtiği dönem 3 öğrencilerinin gün içinde interneti kullanmalarının bilgiye ulaşım amaçlı olabileceğini akla getirmektedir.

GKKÖ puanları ile sigara ve alkol kullanma, düzenli spor yapma durumu ve öğrencilerin not ortalamaları arasında anlamlı bir ilişki bulunmamış ancak yaşamından memnun olan öğrencilerde ölçek değerleri daha düşük bulunmuştur. Benzer şekilde Qutıshat ve ark.'ları da sigara ve alkol kullanma durumu ile ölçek puanları arasında ilişki bulamamıştır [17]. Coşkun ve Muslu da öğrencilerin okul başarısıyla ölçek puanları arasında ilişki bulgulamamıştır [22]. Okul başarısı ya da not ortalamasıyla GKKÖ'nün ilişkili olması beklenirken bunun olmaması şaşırtıcıdır. Yaşam memnuniyeti ile düşük GKK değerlerini gösteren Sha ve ark.'larının çalışmalarında olduğu gibi bireylerin yaşamlarından zevk almaları genel olarak memnun olmaları pek çok ruhsal sorundan, stresten uzak kalarak sosyal ortamlardaki gelişmelerin kaçırılmasından dolayı yaşanan endişeden uzaklaşmalarını sağlamış olabilir [28].

Çalışmanın Sınırlılıkları

Çalışmanın tek bir üniversitedeki Tıp Fakültesinde, sadece 3. sınıf öğrencilerinde yapılması ve dolayısıyla sonuçların tüm sınıflara genelleme yapılamaması gerekmektedir bu da araştırmanın sınırlılıkları arasındadır. Araştırmada bazı verilerin elde edilmesi için sorular kısa tutulmuştur. İnternette geçirilen sürenin hangi amaçla kullanıldığının sorgulanmaması da sinırlılıklar arasındadır.

\section{Sonuç}

Öğrencilerin sosyal ortamlardaki gelişmeleri kaçırma korkuları her ne kadar bazı gruplarda yapılan çalışmalara göre bir miktar düşük bulunsa da tıp öğrencileri açısından da önem göstermektedir. Ayrıca bu korkuyla ilgili olarak öğrencilerin gün içindeki davranışlarının da değiştiği görülmüştür. Nitekim uyumadan önce ve sabah uyanınca bildirimlerini kontrol eden ve ders esnasında bildirimlerine siklıkla bakan öğrencilerde GKKÖ puanları yüksektir. Ayrıca sosyal medya hesaplarına sahip olma yılı ile GKKÖ puanları arasında pozitif bir ilişki görülmüş ve yaşam memnuniyeti yüksek olan öğrencilerinde gelişmeleri kaçırma korkusunun anlamlı olarak düşük olması öğrencilerin stresten kaçış olarak sosyal medyayı kullanma olasılığını akla getirmektedir. Öğrencilere sosyal medya bağımlılı̆̆ 1 hakkında farkındalık sağlayabilecek şekilde müfredatta konuya yer verilmesi ve sosyal destek programlarının artırılması örneğin öğrenciler için kampüs içinde ya da ulaşım sorunu olmayan alanlarda, tüm öğrencileri kapsayıcı, aktif rol alabilecekleri, yaşam memnuniyetlerini artırıcı sosyal etkinliklerin düzenlenmesi ve katılım kolaylığının sağlanması olumlu sonuçlar getirebilir. Ayrıca fakülte yönetiminin internet bağımlılığı, sosyal medya bağımlılığı gibi güncel konuları değerlendirmesi ve öğrencilerin bu konularda farkındalıklarını yükseltecek 
önerileri desteklemesi faydalı olabilir. Araştırmada bazı veriler genel sorularla elde edilmiştir örneğin gün içinde internette geçirilen süre sorgulanırken hangi amaçla kullanıldı̆̆ sorgulanmamıştır, daha sonraki çalışmalarda bunların da sorgulanması aydınlatıcı bir yol sağlayacaktır.

\section{Referanslar}

1.Fox, J, Moreland, J.J, The dark side of social networking sites: An exploration of the relational and psychological stressors associated with Facebook use and affordances, Computers in Human Behavior, 2015, 45, 168-76.

2. Tozkoparan, S.B, Kuzu, A, The Relationship Between Fear of Missing Out (FoMO) Levels and Cyberloafing Behaviors of Teacher Candidates, Anadolu Journal Of Educational Sciences International, 2019, 87-110.

3. Przybylski, A.K, Murayama, K, DeHaan, C.R, Gladwell, V, Motivational, emotional, and behavioral correlates of fear of missing out, Computers in Human Behavior, 2013, 29(4), 1841-8.

4. Gokler, M, Aydin, R, Nal,, E, Metintas S, Determining validity and reliability of Turkish version of Fear of Missing out Scale, Anatolian Journal of Psychiatry, 2016, 17(1), 53.

5. Blackwell, D, Leaman, C, Tramposch, R, Osborne, C, Liss, M, Extraversion, neuroticism, attachment style and fear of missing out as predictors of social media use and addiction, Personality and Individual Differences, 2017, 116, 69-72.

6. Song, X, Zhang, X, Zhao, Y, Song, S, Fearing of missing out (FoMO) in mobile social media environment: Conceptual development and measurement scale, In iConferenre 2017 Proceedings, 2017, 733-738.

Erişim

adresi: https://www.ideals.illinois.edu/bitstream/handle/2142/96709/3.30 _292_Song-

Fearing $\% 20$ of $\% 20$ Missing $\% 20$ Out.pdf?sequence $=1 \&$ isAllowed $=$ $\mathrm{y}$

7.Çankaya, Z.C, Özerklik Desteği, Temel Psikolojik İhtiyaçların Doyumu ve Öznel İyi Olma: Öz-Belirleme Kuramı, Türk Psikolojik Danışma ve Rehberlik Dergisi, 2009, 4(31), 23-31.

8. Hoşgör, H, Kütüncü, S.K, Hoşgör, D.G, Tandoğan, Ö, Üniversite Öğrencileri Arasında Sosyal Medyadaki Gelişmeleri Kaçırma Korkusu Yaygınlığının Farklı Değişkenler Açısından İncelenmesi, International Journal of Academic Value Studies, 2017, 3(17), 213-223.

9. Milyavskaya, M, Saffran, M, Hope, N, Koestner, R, Fear of missing out: prevalence, dynamics, and consequences of experiencing FOMO, Motivation and Emotion, 2018, 42(5), 725737.

10. Kuss, D.J, Griffiths, M.D, Social Networking Sites and Addiction: Ten Lessons Learned, International Journal of Environmental Research. Public Health, 2017, 14(3), 311, 1-17.

11. Beyens, I, Frison, E, Eggermont, S, "I don't want to miss a thing": Adolescents' fear of missing out and its relationship to adolescents' social needs, Facebook use, and Facebook related stress, Computers in Human Behavior, 2016, 64, 1-8.

12. Global Digital Report 2019, We Are Social. Erişim adresi: https://wearesocial.com/global-digital-report-2019 erişim tarihi: 21.10.2020

13. Ezoe, S, Toda, M, Relationships of loneliness and mobile phone dependence with Internet addiction in Japanese medical students, Open Journal of Preventive Medicine, 2013, 03(06), 407-12.

14. Michot, D, Blancot, C, Munoz, B.B, Relationship between Fear of Missing Out and Social Media En- gagement in a French population sample, 2016, Erişim adresi: https://www.spotpink.com/spotpink/wp-content/uploads/MichotBlancot-Bourdon-Baron-Munoz-2016-VF.pdf, erișim tarihi: 06.01.2021

15. Barry, C.T, Sidoti, C.L, Briggs, S.M, Reiter, S.R, Lindsey, R.A Adolescent social media use and mental health from adolescent and parent perspectives, Journal of Adolescence, 2017, 61, 1-11.

16. Alutaybi, A, Al-Thani, D, McAlaney, J, Ali, R, Combating Fear of Missing Out (FoMO) on Social Media: The FoMO-R Method, Interational Journal of Environmental Research Public Health, 2020, 17(17), 6128, 1-28.

17. Qutishat, M, Sharour, L.A, Relationship Between Fear of Missing
Out and Academic Performance Among Omani University Students: A Descriptive Correlation Study, Oman Medical Journal, 2019, 34(5), 404-411.

18. Shoval, D, Tal, N, Tzischinsky, O, Relationship of smartphone use at night with sleep quality and psychological well-being among healthy students: A pilot study, Sleep Health, 2020, 6(4), 495-497.

19. Yuan, G, Elhai, J.D, Hall, B.J, The influence of depressive symptoms and fear of missing out on severity of problematic smartphone use and Internet gaming disorder among Chinese young adults: A three-wave mediation model, Addictive Behaviors, 2020,112, 1-9.

20. Alt D. Students' social media engagement and fear of missing out (FoMO) in a diverse classroom, Journal of Computing in Higher Education , 2017, 29(2), 388-410.

21. Kargın, M, Türkben Polat, H, Coşkun Şimşek, D, Evaluation of internet addiction and fear of missing out among nursing students, Perspective Psychiatic Care, 2020, 56, 726-731.

22. Coskun, S, Karayagız Muslu, G, Investigation of Problematic Mobile Phones Use and Fear of Missing Out (FoMO) Level in Adolescents, Community Mental Health Journal, 2019, 55, 1004 1014.

23. Wolniewicz, C.A, Tiamiyu, M.F, Weeks, J.W, Elhai, J.D, Problematic smartphone use and relations with negative affect, fear of missing out, and fear of negative and positive evaluation. Psychiatry Research, 2018, 262, 618-623.

24. Gezgin, D.M, Hamutoğlu, N.B, Gemikonaklı, O, Raman, İ, Socia Networks Users: Fear of Missing Out in Preservice Teachers, Journal of Education and Practice, 2017, 8, 17, 156-168.

25. Franchina, V, Abeele, M.V, van Rooij, A, Lo Coco, G, De Marez, L, Fear of Missing Out as a Predictor of Problematic Social Media Use and Phubbing Behavior among Flemish Adolescents, International Journal of Environmental Research. Public Health, 2018, 15(10), 2319, 1-18.

26. Dempsey, A.E, O’Brien, K.D, Tiamiyu, M.F, Elhai, J.D, Fear of missing out (FoMO) and rumination mediate relations between social anxiety and problematic Facebook use, Addictive Behaviors Reports, 2019, 9, 1-7.

27. Rozgonjuk, D, Sindermann, C, Elhai, J.D, Montag, C, Fear of Missing Out (FoMO) and social media's impact on daily-life and productivity at work: Do WhatsApp, Facebook, Instagram, and Snapchat Use Disorders mediate that association? Addictive Behaviors, 2020, 110, 106487, 1-9.

28. Sha, P, Sariyska, R, Riedl, R, Lachmann, B, Montag, C, Linking Internet Communication and Smartphone Use Disorder by taking a closer look at the Facebook and WhatsApp applications, Addictive Behaviors Reports, 2019, 9, 100148, 1-9.

http://edergi.cbu.edu.tr/ojs/index.php/cbusbed isimli yazarın CBU-SBED başlıklı eseri bu Creative Commons Alınt1-Gayriticari4.0 Uluslararası Lisansı ile lisanslanmışıtır. 